\title{
Metronidazole for Amoebiasis: A tale of more than half a century
}

${ }^{1}$ Kumanan T, 'Sujanitha V, ${ }^{2}$ SriRanganathan $S$

${ }^{1}$ Faculty of Medicine, University of Jaffna, ${ }^{2}$ Faculty of Medicine, University of Colombo

\section{Abstract}

Metronidazole has many unique properties such as possessing antibacterial as well as anti-protozoal activity, very minimal resistance rate, acceptable safety profile and market longevity. Metronidazole has remained as the recommended drug in the treatment of any form of amoebiasis caused by Entamoeba histolytica since its inception almost half a century ago. Anaphylaxis which limits the use of many antibacterial agents is hardly reported with metronidazole accounting for its favourable safety profile. Owing to its low-cost, it is considered affordable and economically accessible in developing countries which are mainly affected by amoebiasis. Its pharmacokinetic properties considered are its asset as well as drawback. For example, good bioavailability and good tissue penetration allows metronidazole to be used as oral dosage form in many indications and responsible for its efficacy in many extra-intestinal amoebiasis. However, inhibition of hepatic drug metabolizing enzymes is responsible for some significant drug interactions, and disulfiram like effect with alcohol. Unlike many other antimicrobial agents which were discovered much later, metronidazole has withstood the problem of antimicrobial resistance. Even some longer acting agents have been developed in the recent past, metronidazole remains the drug of first choice for amoebiasis documenting very high cure rate with minimal need for other treatment modalities.

\section{Keywords}

amoebiasis, metronidazole, antiprotozoal, antibiotic resistance

\section{Introduction}

Metronidazole belongs to the family of nitro imidazole group of drugs that has selective activity against anaerobic microorganisms, including bacteria and protozoa. At its invention in late 1950s, metronidazole was developed for the treatment of Trichomonas vaginalis infection and subsequently shown to be effective against other protozoans namely Entamoeba histolytica and Giardia lamblia $(1,2,3)$.Currently it has a significant place in the treatment of both intestinal and extra intestinal amoebiasis caused by Entamoeba histolytica, antibiotic associated colitis, anaerobic infections involving lung, gastro intestinal tract and genitalia, as a part of Helicobacter pylori eradication regimen and as prophylaxis before abdominal and gynaecological surgical procedures.

We are all aware of the bitter fact that the modern world of medicine is challenged by the emergence of antimicrobial resistance since the time the first antibiotic emerged. However the role of metronidazole in the treatment of amoebiasis remains unchanged for more than 50 years despite many antimicrobial agents have been forced to disappear due to emergence of resistance. Despite its extensive use over 5 decades, metronidazole remains the preferred drug for any forms of symptomatic amoebiasis including extra intestinal amoebiasis with only a very small proportion requiring percutaneous interventions or any other form of surgical treatment. In addition, it has many advantages including cost effectiveness, good efficacy against susceptible organisms, favourable pharmacokinetics and good tissue penetration (4). Prescribers should prepare the patients for its

Corresponding author: Kumanan T, email: kumanan@univ.jfn.ac.lk, (D https://orcid.org/0000-0001-5735-4713, Submitted December 2020, Accepted May2021

This is an open-access article distributed under the terms of the Creative Commons Attribution 4.0 International License, which permits unrestricted use, distribution and reproduction in any medium provided the original author and source are credited 
adherence limiting adverse effect of metallic taste to get the maximum benefits out of metronidazole.

Despite its long and extensive use in medical practice, studies and trials related to this drug are limited. It is a "time-tested" drug. Its efficacy and safety are established by being in the clinical practice for such a long time without any major setbacks.

The 20th model essential medicine list (EML) published by the World Health Organization(WHO) in 2017 lists metronidazole as an anti-amoebic medicine and as first choice antibacterial agent for Clostridium difficile infections, complicated intraabdominal infections and Trichomonas vaginalis infection and as second choice in mild to moderate complicated intra-abdominal infections (5). It has survived in this regularly updated model EML since the time it was included in 1979 whereas many other agents succumbs to deletion during the revisions.

Metronidazole continued to be listed in the national EML of Sri Lanka as well under the same categories as WHO model EML. Metronidazole is a heavily consumed antimicrobial agent in Sri Lanka. On personal communication the relevant authorities has revealed the fact that the annual consumption in 2016 of metronidazole $200 \mathrm{mg}$ tablet was 42329000 , 400mg tablet was 6662000 and intravenous $500 \mathrm{mg}$ vials was 2349975 . The tentative cost would be LKR 35 million for the tablets and LKR 85million for the parenteral preparation.

Metronidazole is one of the few agents which exhibit the unique property of having both antibacterial and anti-protozoal activities. This article looks at the therapeutic efficacy and use of metronidazole especially in the treatment of amoebiasis based on recent studies.

\section{Amoebiasis}

Amoebiasis is reported from all over the world but seen more in tropical regions with warm climate. Highest incidence is documented from most of the developing countries in the tropics including Sri Lanka. It is known to affect at least 500million people around the world and is responsible for up to 100,000 deaths per annum worldwide (6). It is listed as the third most common cause of death from parasitic diseases.

Amoebiasis is caused by Entamoeba histolytica, the trophozoites being responsible for the clinical illnesses and cysts facilitating the transmission of illness. Amoebiasis is broadly categorized as intestinal and extra intestinal disease. When trophozoites invade the bowel mucosa it causes symptomatic colitis and when it enters the blood it causes distant abscesses in the liver, lungs or brain. Patients with intestinal amoebiasis usually presents with diarrhoea. Profuse diarrhoea is rare. Fulminant colitis which present with severe abdominal pain and high fever is a very rare complication. Other occasional presentations include toxic megacolon, acute fulminant necrotizing amoebic colitis and an amoeboma presenting as a tender mass in the abdomen $(7,8)$.

Invasive colitis and liver abscesses are seven fold more common among men than women. Amoebic liver abscess, the most common extra intestinal amoebiasis has high mortality if not treated promptly (9). However, successful treatment with metronidazole has reduced the mortality almost to zero.

The first report of hepatic amoebiasis from Sri Lanka, formerly known as Ceylon was way back in 1821(10). Since then several reports have been published $(8,11,12)$. Though a study had been conducted in Northern Sri Lanka on immunological and molecular confirmation of amoebiasis recently, diagnosis is mainly based on clinical and ultrasonographic findings (13). Unlike many other infections for which the recommended treatment has changed several times over the years, clinicians in Sri Lanka are able to conquer amoebiasis with oral metronidazole recording high eradication rate and few relapses.

\section{Treatment of amoebiasis}

Anti-amoebic drugs are classified according to the site where the drug is effective: luminal amoebicides which act on luminal form of amoeba mainly the cysts (14), systemic amoebicides which are effective against amoeba in the intestinal wall Jaffna Medical Journal 
and liver mainly the trophozoites (15) and mixed amoebicides which are effective against both the luminal and systemic forms of amoeba, mainly the trophozoites though it is claimed that the luminal concentrations are too low for single drug treatment (16).

Metronidazole is a mixed amoebicidehighly effective against trophozoites of Entamoeba histolytica with no action on cysts. It is rapidly absorbed after oral administration with a bioavailability of over $90 \%$. It's very low luminal concentrations and the necessity to undergo intracellular nitro reduction in order to become active are postulated as the reasons for its ineffectiveness against cysts of Entamoeba histolytica which remain in the lumen. Luminal amoebicides are poorly absorbed with high concentration in the lumen which limits their activity to cysts and trophozoites close to the mucosa $(17,18,19)$.

\section{Treatment of intestinal amoebiasis}

Recommended treatment for amoebic colitis is metronidazole $800 \mathrm{mg}$ orally three times daily for 10days followed by a course of diloxonide furoate $500 \mathrm{mg}$ orally three times a day for 10 days (20) as metronidazole does not eradicate cysts. However, there are no studies published in the recent past which have critically evaluated whether the evidence for this recommendation is robust. Hence clinicians sometimes use only metronidazole. Relapses are not uncommon and probably represent either re-infection as the patients are exposed to same environmental risks or failure to eradicate amoeba from the bowel because of inadequate dosage or duration of therapy.

\section{Treatment of hepatic amoebiasis}

Metronidazole is the drug of choice for hepatic amoebiasis. More than $90 \%$ of patients respond dramatically to metronidazole therapy with resolution of fever and pain within 3 days (21). With early diagnosis and therapy, mortality rate from uncomplicated hepatic amoebiasis is less than $1 \%$ though the abscess disappears slowly over months. The recommended dosage of metronidazole is 500-750mg per oral eight hourly for 7-10 days. In Sri Lanka the tablet strength of metronidazole is $400 \mathrm{mg}$ and clinicians treat hepatic amoebiasis with a course of $800 \mathrm{mg}$ eight hourly for 7-10 days. Majority of patients with liver abscess with no overt intestinal symptoms had shown to harbour the parasites in the intestinal lumen as well. (22). Thus the patients are given a course of luminal amoebicide as well to eradicate the cysts and prevent further transmission. However, recurrence of amoebic liver abscess is very rare. Studies have documented that monotherapy with metronidazole is very effective in treating amoebic liver abscess (23). There is no evidence to suggest that even for large abscesses aspiration accelerates healing induced by metronidazole therapy (24). However percutaneous drainage is indicated in diagnostic dilemmas, lack of clinical response for metronidazole in 3-5days, imminent rupture, left lobe abscess in view of preventing rupture into the pericardium and large abscesses. Open surgical drainage is indicated only in few complicated cases of abscess perforation (25).

\section{Pharmacology of metronidazole}

Metronidazole enters the cell as a prodrug by passive diffusion and is activated either in cytoplasm of the bacteria or specific organelles in the protozoa. In anaerobic microorganisms, metronidazole is converted into an active form by reduction of its nitro group. This binds to DNA and prevents nucleic acid formation by disrupting DNA and causing breakage $(17,18)$.

Metronidazole is well absorbed after oral administration and distributed to achieve sufficient concentration to eradicate infection in the liver, gut wall and pelvic tissue. It is predominantly metabolized in the liver and mainly eliminated via the urine partly as unchanged, partly as metabolites and to a lesser extent via faeces .Its half life is 8 hours and it is prolonged in patients with hepatic impairment (19).

\section{Summary of studies}

Table 1 summarizes the different treatment modalities and their outcome in hepatic amoebiasis. 
Table 1: Summary of studies related to treatment outcome in hepatic amoebiasis

\begin{tabular}{|c|c|c|c|c|}
\hline Author & $\begin{array}{c}\text { Study Design and inter- } \\
\text { ventions }\end{array}$ & Participants and number & Outcome & Findings \\
\hline $\begin{array}{l}\text { Linda CE et } \\
\text { al (26). } \\
\text { Mexico } \\
2014\end{array}$ & $\begin{array}{l}\text { Prospective observational } \\
\text { study. } \\
\text { Intravenous metronidazole } \\
\text { for all participants }\end{array}$ & $\begin{array}{l}\text { amoebic liver abscess (? How } \\
\text { diagnosed) } \\
\text { Say clinically or US } \\
\mathrm{N}=50\end{array}$ & $\begin{array}{l}\text { Improvement in symptoms and } \\
\text { reduction in total white blood } \\
\text { cell count in less than } 72 \text { hours }\end{array}$ & $\begin{array}{l}48 \% \text { required } \\
\text { Percutaneous drainage. }\end{array}$ \\
\hline $\begin{array}{l}\text { McGarr PL } \\
\text { et al( } 27) \\
\text { South Africa } \\
2003\end{array}$ & $\begin{array}{l}\text { Prospective observational } \\
\text { study. } \\
\text { Medical management }\end{array}$ & $\begin{array}{l}\text { Clinically suspected amoebic liver } \\
\text { abscess patients } \\
\mathrm{N}=178\end{array}$ & $\begin{array}{l}\text { Clinical improvement, clinical } \\
\text { deterioration and failure of } \\
\text { clinical improvement (persistent } \\
\text { pain). }\end{array}$ & $\begin{array}{l}13 \% \text { required percutane- } \\
\text { ous aspiration }\end{array}$ \\
\hline $\begin{array}{l}\text { Zafar A et } \\
\text { al(28) } \\
\text { Pakistan } \\
2002\end{array}$ & $\begin{array}{l}\text { Experimental study. } \\
\text { Metronidazole alone Vs } \\
\text { Metronidazole and inter- } \\
\text { ventions }\end{array}$ & $\begin{array}{l}\text { Arm A: Abscess }<300 \mathrm{~cm}^{3} \text { was treat- } \\
\text { ed with metronidazole alone, Arm B: } \\
\text { abscess }>300 \mathrm{~cm}^{3} \text { and smaller ones } \\
\text { which did not respond to metronida- } \\
\text { zole was treated with metronidazole } \\
\text { and needle aspiration }\end{array}$ & $\begin{array}{l}\text { Clinical improvement } \\
\text { Duration of hospital stay } \\
\text { Ultrasound resolution of abscess }\end{array}$ & $\begin{array}{l}\text { Mean time of clinical } \\
\text { improvement } \\
\mathrm{A}=7 \text { days } \\
\mathrm{B}=3 \text { days } \\
\text { Mean hospital stay } \\
\mathrm{A}=7.5 \text { days } \\
\mathrm{B}=3.5 \text { day }\end{array}$ \\
\hline $\begin{array}{l}\text { Bammigatti } \\
\text { C et al (29) } \\
\text { India } \\
2013\end{array}$ & $\begin{array}{l}\text { Randomized control study } \\
\mathrm{A}=\text { Metronidazole alone } \\
\mathrm{B}=\text { ultrasound guided per- } \\
\text { cutaneous aspiration along } \\
\text { with metronidazol }\end{array}$ & $\begin{array}{l}\text { patients with solitary right lobe liver } \\
\text { abscess } \\
\mathrm{N}=57 \\
\text { A-29 } \\
\text { B-28 }\end{array}$ & Resolution of pain and fever & $\begin{array}{l}\text { Resolution of fever and } \\
\text { pain } \\
A=-27 \text { hour } \\
B=17 \text { hour }(\mathrm{P}=0.16 \text { and } \\
0.48 \text {, respectively). }\end{array}$ \\
\hline $\begin{array}{l}\text { Kale A et } \\
\text { al(30) } \\
2017 \\
\text { India }\end{array}$ & $\begin{array}{l}\text { Prospective observational } \\
\text { study } \\
A=\text { Metronidazole alone } \\
B=\text { Needle intervention }\end{array}$ & $\begin{array}{l}\text { patients with uncomplicated amoebic } \\
\text { liver abscess } \\
\mathrm{N}=60\end{array}$ & $\begin{array}{l}\text { 1.Length of hospital stay } \\
\text { 2.Complications }\end{array}$ & $\begin{array}{l}\text { The length of hospital stay } \\
\mathrm{A}=4.8 \pm 0.9 \text { days } \\
\mathrm{B}=7.1 \pm 2.4 \text { days } \\
\mathrm{P}<0.001\end{array}$ \\
\hline $\begin{array}{l}\text { Garale MN } \\
\text { et al(31) } \\
2016 \\
\text { India }\end{array}$ & $\begin{array}{l}\text { Observational study } \\
\mathrm{A}=\text { Metronidazole alone } \\
\mathrm{B}=\text { Metronidazole and per- } \\
\text { cutaneous aspiration } \\
\mathrm{C}=\text { Metronidazole and } \\
\text { percutaneous drainage }\end{array}$ & $\begin{array}{l}\text { patients with amoebic liver abscess } \\
\mathrm{N}=100\end{array}$ & $\begin{array}{l}\text { 1.Mean percentage reduction in } \\
\text { the volume of abscess } \\
\text { Necessity for interventions }\end{array}$ & $\begin{array}{l}\text { A- } 18.56 \% \\
\text { B- } 73.2 \% \\
\text { c-93.34\% }\end{array}$ \\
\hline
\end{tabular}

\section{Resistance data for metronidazole}

Problem of drug resistance appears to be low with metronidazole compared to other antibacterial and antiprotozoal agents (15). Even within metronidazole, Entamoeba histolytica developing resistance is reported to be lower than that of anaerobes and other parasites $(32,33)$. While many antibiotics stay in the market only for a short period due to bacteria developing resistance (34), metronidazole has withstood this problem and in the market as the preferred drug for Entamoeba histolytica over 5 decades. However, the occasional reports of failed treatment with metronidazole and differences noted in drug susceptibilities forewarn development of drug resistance clinically (35). This can happen soon if asymptomatic individuals are irrationally treated with metronidazole. In authors' experience, this appears to be low in Sri Lanka. Asymptomatic infections are mainly caused - 9 - by Entamoeba dispar which is morphologically similar to Entamoeba histolytica (35). Possible mechanisms of drug resistance includes parasites evading the drugs by hiding in sanctuaries, loss of a transporter required for uptake, efflux of the drug after uptake, alteration of the drug target and loss of drug activation $(36,37)$. Owing to diploid nature of genetic material of luminal parasites, mechanisms of drug resistance acquired by changes in a single gene in these parasites is a slow process and not sufficient to confer drug resistance (38).

\section{Experience on treatment of hepatic amoebiasis in Northern Sri Lanka}

For a considerable period of time, physicians in the Northern Sri Lanka have been treating patients with hepatic amoebiasis who are usually referred either from private clinics or peripheral Government hospital (13). The diagnosis is based on history, 
examination findings and investigations mainly ultrasonography. The latter play a major role in confirming the diagnosis. The patients are usually young and middle aged men who consume alcohol in the form of toddy (a variety of palm wine). Poverty, poor sanitation, post war displacement, and malnutrition appeared to be other contributory factors. They usually present with fever, right hypochondrial pain, loss of appetite and significant intercostal tenderness. Leucocytosis, elevated erythrocyte sedimentation rate and alkaline phosphatase are commonly observed in these patients. An abdominal ultrasonography usually confirms an abscess commonly in the right lobe of the liver.

A study conducted in Teaching hospital Jaffna (Tertiary Hospital, Northern Province) between 2012 and to 2014 on 345 suspected patients with amoebiasis revealed that $99.7 \%$ of serum samples were positive for IgG antibody against $\mathrm{E}$. Histolytica and $99.4 \%$ of serum and $100 \%$ of pus samples were positive for E. histolytica antigen. This provided the first immunological confirmation of the clinical diagnoses of hepatic amoebiasis in Northern Sri Lanka (13). These patients were mainly treated with a course of metronidazole for 7-10 days with some undergoing percutaneous aspiration.

Theoretically, hepatic amoebiasis is generally preceded by an asymptomatic intestinal infection which needs treatment with luminal amoebicides as well. However, majority of these patients were not treated with luminal amoebicides due to nonavailability of these drugs. Interestingly, same patients presenting with recurring symptoms were hardly noted though we do not have exact figures.

\section{Limitations of use of metronidazole in clinical practice}

Though serious adverse effects are extremely rare with metronidazole when it is used rationally, (17) in some occasions few troublesome adverse effects and pharmacokinetic properties limit its use in clinical practice.

Vol.33, No.1, July 2021
Adverse effects like unpleasant metallic taste, nausea, vomiting, diarrhoea, and furred tongue are known to affect adherence to treatment. Drowsiness and dizziness though reported less frequently can seriously affect the work ability of users. Since majority are young to middle aged males doing unskilled manual works, these adverse effects can expose them to occupational injuries such as fall and accidents. Dark brown discoloration of urine though rare and benign can impair adherence and results in unnecessary visits to doctors if patients are not warned about this innocent side-effect. Metronidazole inhibits alcohol and aldehyde dehydrogenase and precipitates disulfiram like effect if the patients consume alcohol concurrently (18). Advising the patients about this issue may affect the adherence as the patients who are addicted to alcohol may opt to discontinue metronidazole. Not informing about the issue will expose the patients to distressing symptoms of disulfiram like effect such as flushing, throbbing headache, sweating, respiratory difficulty and could lead to hospitalization even. Individual case by case decision had to be made by the prescriber in dealing with this issue.

Serious adverse effects such as peripheral neuropathy, leucopoenia, seizures and ataxia are rare, occurs with high doses and intravenous administration and often reversible.

Large doses of metronidazole are carcinogenic in rodents and the drug is mutagenic in bacteria, however long term studies in human did not show such effect (39). However large doses and prolonged therapy are not practiced in the treatment of amoebiasis.

Manufacturers advise to avoid metronidazole during pregnancy and breast feeding (40). Metronidazole crosses placental barrier and its effects on human fetal organogenesis are not known; reproduction studies in animals at doses similar to maximum recommended daily dose for humans did not document any harm to fetus due to metronidazole (41). Obviously there are no well controlled clinical trials on risk of teratogenicity, 
but the other studies like cohort studies, metaanalysis and case control studies have reported data from 5000 pregnant women who were exposed to metronidazole many during first trimester. One such study reported increased risk of cleft lip with or without cleft palate (42). Metronidazole is one of the few drugs which is present in human milk at concentrations similar to maternal serum levels, and infant serum levels are generally close to or equal to infant therapeutic levels. Because of potential carcinogenicity documented in mouse and rat studies, it is preferable to avoid metronidazole and look for alternatives for female patients from developing countries who are nursing their infants as discontinuing breast feeding can be more disadvantageous. However this is not of a major problem in the treatment of amoebiasis as it is rarely occurs in female of reproductive age group.

Metronidazole is known to inhibit hepatic drug metabolizing cytochrome enzyme CYP3A4. Coadministration of metronidazole and CYP3A4 substrates (e.g., amiodarone, tacrolimus, cyclosporine, carbamazepine, phenytoin, and quinidine) may increase respective CYP3A4substrate plasma levels though clinically significant outcomes with the dose and duration of metronidazole used in the treatment of amoebiasis are rarely reported $(43,44)$. Metronidazole is known to potentiate the effect of warfarin and increase the risk of busulphan toxicity when coadministered with these drugs. It is imperative that the risk versus benefit should be assessed when coprescribing these drugs and adequate precautions have to be taken to monitor patients if such coprescription is unavoidable.

Pharmacokinetically, metronidazole has some disadvantages, mainly its relatively short plasma elimination half-life ( 8 hours) requiring 3 times daily dose and its ability to inhibit some hepatic drug metabolizing enzymes.

Long acting nitroimidazole such as tinidazole and ornidazole have been effective as single dose therapy or for shorter duration. Though studies have reported subtle differences in the side-effect profile, -11 - metronidazole still remain the preferred agent to treat amoebiasis (45).

\section{Open for research}

Though metronidazole is effectively used in the clinical practice to treat hepatic amoebiasis for a long time, there are no well conducted studies in the literature reporting its efficacy rate, frequency of adverse effects and clinically relevant drug interactions. In addition, the long standing recommendation of adding a luminal amoebicides when hepatic amoebiasis patients are treated with metronidazole also needs to be researched using clinical, pharmacodynamic and pharmacokinetic end points in countries wher it is highly prevalent.

\section{Conclusion}

To conclude, metronidazole in the treatment of amoebiasis has all the ideal properties which we would like to have for the agents used in all infections: effective, acceptable safety profile, cheap, widely available, and insignificant resistance rate.

\section{Conflict of interest}

The authors declare that there is no conflict of interest in preparation of this article.

\section{References}

1. Petrin D, Delgaty K, Bhatt R, Garber G. Clinical and microbiological aspects of Trichomonas vaginalis. Clin Microbiol Rev. 1998; 11(2):300-17.

2. Ravdin JI. Amebiasis. Clin Infect Dis. 1995; 20(6):1453-64

3. Zaat JO, MankTG, Assendelft WJ.A systematic review on the treatment of giardiasis. Trop Med Int Health. 1997; 2 (1):63-82.

4. RalphED. Clinical pharmacokinetics of metronidazole.ClinPharmacokinet.1983; $8(1): 43-62$.

5. WHO model list of Essential Medicines.20th list (March 2017) amended August 2017).

Jaffna Medical Journal 
http://www.who.int/medicines/publications/ essentialmedicines/en/

6. Amoebiasis. Wkly Epidemiol Rec. 1997 Apr 4; 72(14):97-9.

7. Raviraj S, Sivashankar M, Ekanayake A. A rare and potentially fatal complication of amoebiasis: Acute fulminant necrotizing amoebic colitis. Ceylon Med J.2017; 62(1):6364

8. Ratnasamy V, Thirunavukarasu K, Selvam $\mathrm{K}$, Arumugam M. Amoebic liver abscess: an unusual cause for a right iliac fossa mass: a case report. BMC Infectious diseases.2016; 16:741

9. Wuerz T, Kane JB, Boggild A et al. A review of amoebic liver abscess for clinicians in a non-endemic setting. Can J Gastroenterl.2012; 26(10):729-733

10. Rajasuriya K, Nagaratnam N. Hepatic amoebiasis in Ceylon. J Trop Med Hyg.1962; $65: 165-78$

11. Cavailloles FA, Mure A, Nasser H, Lecapitaine AL, Granier F. Multiple liver amoebic abscesses detected on FDG PET/CT. Clin Nucl Med. $2014 ; 39(1): 79-80$.

12. Stephen SJ, Uragoda CG. Pleuro-pulmonary amoebiasis: A review of 40 cases. Br J Dis Chest.1970; 64(2):96-102

13. Kannathasan S, Murugananthan A, Kumanan $\mathrm{T}$ et al. Amoebic liver abscess in northern Sri Lanka: first report of immunological and molecular confirmation of aetiology. Parasit Vectors. 2017; 10: 14.

14. CosarC, Julou L.Activity of 1-(2-hydroxyethyl)2-methyl-5-nitroimidazole(8823RP)against experimental Trichomonas vaginalis infection. Ann Inst.Pasteur.1959;96:238-241.

15. Lofmark S,Edlund C,Nord CE.Metronidazole is still the drug of choice for treatment of anaerobic infections. Clinical infectious diseases.2010; 50(1):S16-23.
16. Shinn DLS. Metronidazole in acute ulcerative gingivitis.Lancet.1962; 279:1191

17. Rosenthal PJ. Antiprotozoal drugs. Basic and clinical pharmacology.13th edition. Chapter 52.McGraw Hill Education Lange.2015; 898-9

18. Rang HP, Dale MM, Ritter JM, Flower RJ, Henderson G. Rang and Dale's Pharmacology.7th edition. Elsevier Churchill Livingstone.2012:605-6

19. Bennet PN, Brown MJ, Sharma PJ. Infection and inflammation-antibacterial drugs. Clinical Pharmacology.11th edition. Churchill Livingstone Elsevier.2012:188-9.

20. Stanley SL Jr.Amoebiasis.Lancet.2003; 361:1025-34

21. Petri WA, Singh U. Diagnosis and Management of Amebiasis. Clinical Infectious Diseases.1999; 29(5):1117-1125.

22. Seeto RK, Rockey DC. Amoebic liver abscess: Epidemiology, clinical features and outcome. West J Med.1999; 170:104-109

23. Gonzales ML, DansLF, Martinez EG. Antiamoebic drugs for treating amoebic colitis. Cochrane Database Syst Rev.2009;2: CD006085.

24. Blessmann J, Binh HD, Hung DM, Tannich E, Burchard G. Treatment of amoebic liver abscess with metronidazole alone or in combination with ultrasound guided aspiration: a comparative, prospective and randomised study. Trop Med Int Health.2003; 8(11):1030-4

25. Sayek I, Onat D. Pyogenic and amoebic liver abscess. Surgical treatment: Evidence based and problem oriented. Munich: Zuckschwerdt; 2001.

26. Linda AC, Jorge ES, Panduro A, Laura EM. Amebic Liver Abscess: A New Perspective on the Prognosis of Patients in an Endemic Area Regional Referral Center. J Liver 2014; 3:1. http://dx.doi.org/10.4172/2167-0889.1000142 
27. McGarr PL, Madiba TE, Thomson SR, Corr P. Amoebic liver abscess - results of a conservative management policy. S Afr Med J.2003; 93: 132-136.

28. Zafar A, Ahmed S. Amoebic liver abscess: a comparative study of needle aspiration versus conservative treatment. . J Ayub Med Coll $.2002 ; 14(1): 10-2$

29. Bammigatti C, Ramasubramanian NS, Kadhiravan T,Das AK. Percutaneous needle aspiration in uncomplicated amebic liver abscess: a randomized trial Trop Doct.2013; 43(1):19-22

30. Kale S, Nanavati AJ, Borle N, Nagral S. Outcomes of a conservative approach to management in amoebic liver abscess. J Postgrad Med.2017; 63(1):16-20

31. Garale MN, Takalkar YP, Ingale PR. A study of the different treatment modalities used in the management of amoebic liver abscesses. International Surgery Journal.2016; 3(4):19111915

32. Gosciniakl G, Glupcxynski Y, Goutier S et al. Prevalence of antibiotic resistance in Helicobacter pylori strains in Poland. Clin Microbiol Infect 1998; 4: 726-728.

33. Upcroft P, Upcroft JA. Drug taergets and mechanisms of resistance in the anaerobic protozoa. Clin Microbiol Rev.2001; 14 (1):150164

34. Ventola CL. The antibiotic crisis, Part 1: Causes and threats.PT.2015;40(4):277-283

35. BansalD, SehgalR, ChawlaY, Malla N, Mahajan RC. Multidrug resistance in amoebiasis patients. Indian J Med Res.2006:189-194.

36. Borst P, Ouellette M. New mechanisms of drug resistance in parasitic protozoa. Annu Rev Microbiol. 1995;49: 427-60.
37. Wassmann C, HellbergA, Tannich E, Bruchhaus I. Metronidazole resistance in the protozoan parasite Entamoeba histolytica is associated with increased expression of iron-containing superoxide dismutase and peroxiredoxin and decreased expression of ferredoxin 1 and flavin reductase. J Biol Chem.1999; 274(37):260516.

38. Samuelson J. Why metronidazole is active against both bacteria and parasites. Antimicrob Agents Chemother.1999; 43(7):1533-1541

39. Bendesky A, Menendez D, Ostrosky-Wegman P.Is metronidazole carcinogenic? Mutat Res.2002; 511(2):133-44.

40. British National Formulary 70.5-Nitroimidazole derivatives-metronidazole. British Medical Association \& Royal Pharmaceutical Society.2016:475-476

41. Burtin P, Taddio A, Ariburnu O, Einarson TR, Koren G. Safety of metronidazole in pregnancy: a meta-analysis. Am J Obstet Gynecol. 1995; 172(2 Pt 1):525-9.

42. UK summary of product Characteristics.

43. Roedler R, Neuhauser MM, Penzak SR. Does metronidazole interact with CYP3A substrates by inhibiting their metabolism through this metabolic pathway? Or should other mechanisms be considered? Ann Pharmacother.2007; 41(4):653-8.

44. Haas CE, Kaufman DC, DiCenzo RC. Effects of metronidazole on hepatic CYP3A4 activity. Pharmacotherapy. 2001; 21(10):1192-5.

45. Bassily S, Farid Z, el-Masry NA, Mikhail EM. Treatment of intestinal E.histolytica and G.lamblia with metronidazole, tinidazole and ornidazole: a comparative study. J Trop Med Hyg.1987;90 (1):9-12 